\title{
Association of Vascular Endothelial Growth Factor (VEGF) and VEGF Receptor Gene Polymorphisms with Coronary Artery Lesions of Kawasaki Disease
}

\author{
HIDEHIKO KARIYAZONO, TAKURO OHNO, VAHID KHAJOEE, KENJI IHARA, \\ KOICHI KUSUHARA, NAOKO KINUKAWA, YUMI MIZUNO, AND TOSHIRO HARA
}

Department of Pediatrics, [H.K., T.O., V.K., K.I., K.K., T.H.] Graduate School of Medical Sciences, Kyushu University, Fukuoka 812-8582, Japan; Department of Medical Informatics [N.K.], Graduate School of Medical Sciences, Kyushu University, Fukuoka 812-8582, Japan; Department of Pediatrics [Y.M.], Fukuoka Children's Hospital, Fukuoka 810-0063, Japan

\begin{abstract}
We analyzed the genetic polymorphisms of vascular endothelial growth factor (VEGF) and its receptors [Fms-related tyrosine kinase-1, kinase insert domain receptor (KDR)] in Japanese patients with Kawasaki disease (KD) and normal control subjects to examine whether these genes would contribute to the KD occurrence and/or the development of coronary artery lesion (CAL) in KD. We found that the frequency of $\mathrm{G}$ allele of VEGF g. $-634 \mathrm{G}>\mathrm{C}$ single-nucleotide polymorphism in the promoter region was significantly higher in KD patients with CAL than in those without CAL $(p=0.012)$ or control subjects $(p=0.021)$ because of a significantly higher frequency of the GG genotype in $\mathrm{KD}$ patients with CAL. In addition, the frequency of the $\mathrm{A} 1$ allele with 11 AC repeats of KDR g. +4422 (AC)11-14 dinucleotide repeat polymorphism in intron 2 was significantly higher in KD patients with CAL than in those without CAL $(p=0.013)$ or control subjects $(p=0.040)$ as a result of a significantly higher frequency of the A1A1 genotype in KD with CAL patients. The multivariate analysis of clinical features and genotypes of the two polymorphisms showed that the A1A1 genotype of KDR g. +4422 (AC)11-14 polymorphism was an independent risk fac-
\end{abstract}

\section{ABSTRACT}

tor for the development of CAL with the highest odds ratio among several clinical parameters (odds ratio 6.76; 95\% confidence interval 1.05-43.48). Dual luciferase assay demonstrated that the A1 allele with KDR g. $+4422(\mathrm{AC}) 11$ repeats showed a weaker silencer function than the A2 allele with $12 \mathrm{AC}$ repeats. These findings suggested that VEGF and its receptor, KDR, genes contributed to the development of CAL in KD patients. (Pediatr Res 56: 953-959, 2004)

$\quad$ Abbreviations
ARNT, aryl hydrocarbon receptor nuclear translocator
CAL, coronary artery lesion
FLT-1, Fms-related tyrosine kinase-1
HUVEC, human umbilical vein endothelial cell
IVIG, i.v. immunoglobulin
KD, Kawasaki disease
KDR, kinase insert domain receptor
SNP, single-nucleotide polymorphism
VEGF, vascular endothelial growth factor

Kawasaki disease (KD) is an acute febrile vasculitis of infants and children and is accompanied by the coronary artery lesions (CALs) that occur in $\sim 5-16 \%$ of patients $(1,2)$. Even after the introduction of high-dose i.v. immunoglobulin (IVIG) therapy, CAL occurs in a small proportion of KD patients and leads to life-threatening complications, including myocardial

Received November 12, 2003; accepted April 8, 2004.

Correspondence: Hidehiko Kariyazono, M.D., Department of Pediatrics, Graduate School of Medical Science, Kyushu University, 3-1-1, Maidashi, Higashi-ku, Fukuokashi, Fukuoka 812-8582, Japan; e-mail; hide-k@mailserver.med.kyushu-u.ac.jp

This study was supported by the grants from the Ministry of Education, Culture, Sports, Science and Technology of Japan.

DOI: 10.1203/01.PDR.0000145280.26284.B9 infarction, as well as acquired heart diseases such as myocardial dysfunction, valvular diseases, and arrhythmias $(3,4)$. Therefore, it is important to identify as early as possible KD patients who are at risk for the development of CAL.

During the acute stage of KD, activation of the immune system with increased serum cytokines such as tumor necrosis factor- $\alpha$, interferon- $\gamma$, IL-1, IL-2, IL-6, and IL- 8 may play important roles in the occurrence of endothelial cell injury (5-7). The pathologic findings of vascular tissues in KD patients include subendothelial edema, vascular damage, gap formation, and fenestration of endothelial cells $(8,9)$. Vascular endothelial growth factor (VEGF) is a molecule that promotes microvascular hyperpermeability and two major receptors for 
VEGF, known as VEGF-R1 [fms-related tyrosine kinase-1 (FLT-1)] and VEGF-R2 [kinase insert domain receptor $(\mathrm{KDR})]$, are expressed exclusively in vascular endothelial cells. Because systemic overproduction of VEGF has been demonstrated in acute KD, VEGF is considered to be involved in the pathophysiology of $\mathrm{KD}$, especially in the development of CALs (10-14). In contrast to the other cytokines described above, which are largely produced by immune cells, VEGF in $\mathrm{KD}$ seems to be produced mainly by vascular smooth muscle cells (14). If stimulation or destruction of smooth muscle cells by inflammation of surrounding vascular tissues induces VEGF release from the cells, then it is suggested that serum VEGF levels reflect the severity of vasculitis. From a clinical point of view, serum VEGF level at diagnosis was found to be an independent major risk factor for the occurrence of CALs (12).

In previous reports, several genetic polymorphisms, such as tumor necrosis factor- $\alpha$ gene and CD14 gene, were associated with KD occurrence and/or the development of CALs $(15,16)$. However, these studies did not include functional assays or multivariate analysis with clinical data. With respect to the VEGF gene, recent studies have shown that two genetic polymorphisms regulate the production of VEGF protein (17-19). On the assumption that these genetic variations of VEGF and its receptor genes influence the systemic production of VEGF and its effects on vascular endothelial cells in KD patients and consequently contribute to the development of CALs, we analyzed the genetic polymorphisms of VEGF and its receptor genes in KD patients and investigated whether these genes would contribute to the KD occurrence or the development of CALs.

\section{METHODS}

Patients and control subjects. The diagnosis of KD was made by the clinical criteria of the Japan Kawasaki Disease Research Committee (20), and the CAL was defined as the lumen diameter being at least $3 \mathrm{~mm}$ ( $>5 \mathrm{y}$ of age, $4 \mathrm{~mm}$ ) or the internal diameter of a segment at least 1.5 times as large as that of an adjacent segment (21). The clinical courses, initial laboratory data on admission, and echocardiograms or cardiac catheterization findings were examined retrospectively from their medical records. Informed consent was obtained from patients or their parents before study, and the Ethical Commit- tees of Kyushu University and Fukuoka Children's Hospital approved the study. The study population consisted of $41 \mathrm{KD}$ patients with CAL ( 28 boys and 13 girls) and 62 without CAL (37 boys and 25 girls) and 144 healthy control subjects. The age at diagnosis was $25.1 \pm 23.6$ mo (mean \pm SD). All patients received acetylsalicylic acid, and $87(84.5 \%)$ patients received IVIG and their initial administration was on day $5.2 \pm$ 2.0 (mean $\pm \mathrm{SD}$ ) of illness. Other clinical and laboratory data are shown in Table 1.

DNA extraction. Genomic DNA was extracted from wholeblood leukocytes with QIAamp blood kit (Qiagen, Tokyo, Japan).

Nomenclature for polymorphisms. The description of polymorphisms in this article is based on the nomenclature recommendations by den Dunnen et al. (22). Nucleotide +1 is the A of the ATG-translation initiation codon, and the nucleotide 5' to +1 is numbered -1 . A letter preceding the description indicates the type of reference sequence as follows: g. for genomic sequence and c. for cDNA sequence.

Restriction fragment length polymorphism analysis of VEGF gene polymorphisms. Restriction fragment length polymorphism analysis of VEGF g. $-634 \mathrm{G}>\mathrm{C}$ and g. +13553 $\mathrm{C}>\mathrm{T}$ single nucleotide polymorphisms (SNPs) was carried out as described previously $(17,18)$.

Genotyping of KDR gene polymorphisms for association study. Eight SNPs and one AC repeat polymorphism were obtained from the National Center for Biotechnology Information database (accession no. NT_0022853) and are as follows: two (g. $+11903 \mathrm{G}>\mathrm{A}$ and g. $+18487 \mathrm{~A}>\mathrm{T}$ ) in that coding region that causes amino acid changes; five (g. $-907 \mathrm{~T}>\mathrm{C}$, g. $-680 \mathrm{G}>\mathrm{A}$, g. $-608 \mathrm{~T}>\mathrm{C}$, g. $-566 \mathrm{C}>\mathrm{T}$, g. $-273 \mathrm{G}>\mathrm{A})$ in the promoter region; one (g. $+1786 \mathrm{~T}>\mathrm{A})$ in intron 1; and one AC repeat polymorphism [g. $+4422(\mathrm{AC}) 11-14]$ in the intron 2, which was previously reported as a deletion/insertion polymorphism (National Center for Biotechnology Information SNP cluster ID: rs3034659).

All PCRs for genotyping were carried out under the same condition ( 35 cycles of denaturation at $94^{\circ} \mathrm{C}$ for $30 \mathrm{~s}$, annealing for $30 \mathrm{~s}$, and extension at $72^{\circ} \mathrm{C}$ for $30 \mathrm{~s}$ ) with various annealing temperatures for respective amplifications. Table 2 shows all primer sequences for determination of KDR gene polymorphisms and their melting temperatures.

Table 1. Clinical and laboratory data of KD patients

\begin{tabular}{|c|c|c|c|c|}
\hline Variables & $\begin{array}{c}\mathrm{CAL}+/- \\
(n)\end{array}$ & $\begin{array}{c}\text { With CAL } \\
\text { [median (range)] }\end{array}$ & $\begin{array}{c}\text { Without CAL } \\
\text { [median (range)] }\end{array}$ & $p$ value* \\
\hline Age (mo) & $41 / 62$ & $15(1-113)$ & $20(2-105)$ & 0.325 \\
\hline Admission (day of illness) & $41 / 62$ & $4(1-13)$ & $5(1-9)$ & 0.921 \\
\hline Duration of fever (days) & $41 / 62$ & $10(4-27)$ & $6(3-11)$ & $<0.01 \dagger$ \\
\hline White blood cell $\left(\times 10^{3} / \mu \mathrm{L}\right)$ & $37 / 62$ & $13.7(5.5-31.0)$ & $13.0(6.2-23.5)$ & 0.454 \\
\hline Peak white blood cell $\left(\times 10^{3} / \mu \mathrm{L}\right)$ & $32 / 46$ & $16.8(7.3-35.9)$ & $15.1(7.9-28.2)$ & $0.036 \dagger$ \\
\hline C-reactive protein $(\mathrm{mg} / \mathrm{dL})$ & $38 / 62$ & $9.4(2.7-27.4)$ & $7.1(2.0-23.9)$ & $0.027 \dagger$ \\
\hline Peak C-reactive protein $(\mathrm{mg} / \mathrm{dL})$ & $34 / 52$ & $10.6(3.3-32.4)$ & $7.9(2.0-23.9)$ & $0.007 \dagger$ \\
\hline Total protein $(\mathrm{g} / \mathrm{dl})$ & $23 / 54$ & $6.4(4.5-7.5)$ & $6.6(5.4-7.6)$ & 0.070 \\
\hline
\end{tabular}

* Mann-Whitney $U$ test.

$\dagger$ Significant difference $(p<0.05)$. 
Table 2. Primers for genotyping of KDR gene polymorphisms

\begin{tabular}{|c|c|c|c|c|}
\hline Polymorphisms & Region & Primers & $\operatorname{Tm}\left({ }^{\circ} \mathrm{C}\right)$ & Amplicon size (bp) \\
\hline \multirow[t]{2}{*}{ g. $+11903 \mathrm{G}>\mathrm{A}$} & Exon 7 & F: CGAGACCTAAAAACCCAGTCTGG & 60 & 129 \\
\hline & & R: CTTCTTGGTCATCAGCCCACT & 58 & \\
\hline g. $+18487 \mathrm{~A}>\mathrm{T}$ & Exon 11 & F: GGTAGGCTGCGTTGGAAGTTATT & 60 & 188 \\
\hline \multirow[t]{2}{*}{ g. $-273 \mathrm{G}>\mathrm{A}$} & Promoter & F: AGCTCCCACCCTGCACTGA & 60 & 266 \\
\hline & & R: TCCCAGCGCCTGTCTAGAG & 58 & \\
\hline \multicolumn{5}{|l|}{ g. $-566 \mathrm{C}>\mathrm{T} 7$} \\
\hline \multicolumn{5}{|l|}{ g. $-907 \mathrm{~T}>\mathrm{C}$} \\
\hline \multirow[t]{2}{*}{ g. $+1786 \mathrm{~T}>\mathrm{A}$} & Intron 1 & F: ATTTGAAGTTATTGAGAGCCTTGT & 54 & 204 \\
\hline & & R: CGGCTACCAAAATCAGAAAC & 54 & \\
\hline \multirow[t]{2}{*}{ g. $+4422(\mathrm{AC}) \mathrm{n}$} & Intron 2 & F: GCTTGTAGTAATTGTTCATAAGTGG & 53 & $225-231$ \\
\hline & & R: GAGCGTATGTCTACTATACGCCA & 55 & \\
\hline
\end{tabular}

Tm, melting temperature.

The g. $+11903 \mathrm{G}>$ A SNP in exon 7 was amplified by PCR and determined by single-strand conformation polymorphism analysis with Gene Gel Excel 12.5/24 (Amersham Pharmacia Biotec, Uppsala, Sweden), according to the manufacturer's instructions. Single-strand DNA fragments in gel were visualized by subsequent silver staining. The g. $+18487 \mathrm{~A}>\mathrm{T}$ SNP in exon 11 was amplified by PCR, and the PCR products were digested with Nla III (New England Biolabs, Beverly, MA), and restriction fragment length polymorphism analysis was carried out by electrophoresis on $2 \%$ agarose gel and visualization with ethidium bromide staining. The 188-bp PCR product with $\mathrm{g} .+18487 \mathrm{~T}$ was digested into 124- and 64-bp fragments, whereas that with g. +18487 A was not. The five SNPs (g. $-273 \mathrm{G}>$ A, g. $-566 \mathrm{C}>\mathrm{T}$, g. $-608 \mathrm{~T}>\mathrm{C}$, g. -680 $\mathrm{G}>\mathrm{A}$, and g. $-907 \mathrm{~T}>\mathrm{C}$ ) in the promoter region were genotyped by PCR-mediated direct sequencing. The g. $+1786 \mathrm{~T}>\mathrm{A}$ SNP in intron 1 was amplified by PCR and determined by single-strand conformation polymorphism as described above. The DNA with g. +4422(AC)11-14 dinucleotide repeat polymorphism site was amplified by PCR. The 5 ' end of the forward primer was labeled with 6-carboxyfluorescein dye. Genotyping was performed using a fluorescence-based technique by an ABI prism 310 genetic analyzer and GeneScan analysis software (Perkin-Elmer).

Genotyping of FLT-1 gene microsatellite polymorphisms using PCR and a fluorescence-based technique. The FLT1 c. +6724 (TG)13-23 polymorphism site was amplified by PCR as described previously (23). Genotyping with a fluorescencebased technique was performed as described above.

Functional analysis of KDR g. +4422(AC)11-14 polymorphism by dual luciferase assay. The constructs used in the analysis are shown in Fig. 1. The pKDR-LUC plasmid was pGL3-Basic vector (Promega) with the KDR promoter region from -417 to -6 (24) incorporated into the KpnI-SacI site. A 937-bp KDR DNA fragment from +4111 to +5047 containing the polymorphism site was obtained from homozygous individuals and subcloned into the SacI-MluI site of pKDR-LUC plasmid. All PCRs for KDR DNA fragments were used with Pfu Turbo DNA polymerase (Stratagene, La Jolla, CA), and the constructs were verified by sequencing analysis.

Human umbilical vein endothelial cells (HUVECs) and HeLa cells were cultured in HuMedia-EG2 medium (Kurabo,

\section{PKDR-LUC}

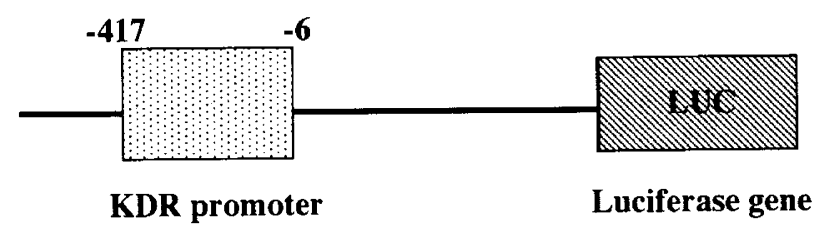

\section{pKDR-(AC)n-LUC}

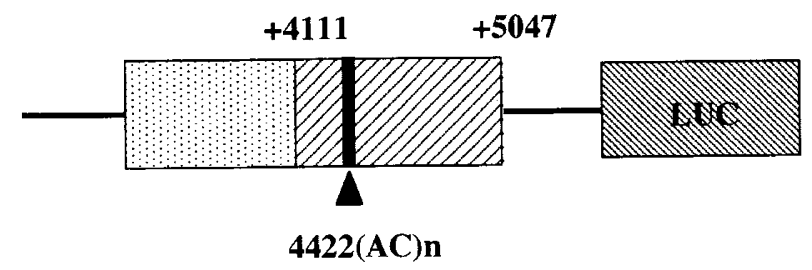

Figure 1. pKDR-LUC plasmid: A 412-bp KDR promoter region was incorporated upstream of the luciferase gene (LUC) into pGL3-Basic Vector. pKDR-(AC)n-LUC plasmid: A 937-bp fragment containing a polymorphism site was incorporated downstream of the KDR promoter region in pKDR-LUC plasmid.

Osaka, Japan) and in Dulbecco's modified Eagle's medium supplemented with $10 \%$ FCS and $50 \mu \mathrm{g} / \mathrm{mL}$ streptomycin, respectively, at $37^{\circ} \mathrm{C}$, under $95 \%$ humidified air, with $5 \% \mathrm{CO}_{2}$.

HUVECs and HeLa cells were suspended and seeded into six-well plates $\left(3 \times 10^{5}\right.$ cells/well). One day later, $0.1 \mu \mathrm{g}$ of each vector and $0.1 \mu \mathrm{g}$ of Renilla luciferase vector (pRL-TK Renilla), as internal control, were introduced into HUVECs and HeLa cells by the lipofection method using Lipofectamine plus (GIBCO BRL, Gaithersburg, MD). Twenty-four hours later, firefly and Renilla luciferase activities were measured using the Dual-Luciferase Reporter Assay System (Promega). Luciferase activity was calculated as the ratio of firefly to Renilla luciferase activity. Transfections were performed in duplicate for each vector and repeated three times.

Statistics. For the evaluation of clinical and laboratory data, a Mann-Whitney $U$ test was used to compare parameters between groups with and without CAL. As for genotyping, the 
fit to Hardy-Weinberg equilibrium was tested by calculating the $\chi^{2}$ for goodness of fit. Differences of allele or genotype frequencies between groups were evaluated by $\chi^{2}$ analysis. A value of $p<0.05$ was considered statistically significant. When frequencies of three genotypes were compared, corrected $p$ values $(p c)$ were obtained by multiplying the uncorrected $p$ values by 3 using Bonferroni inequality method. A value of $p c<0.05$ was considered significant. Haplotype frequencies for pairs of alleles in the KD population $(n=103)$ were estimated using the estimating haplotype frequencies software program (http://linkage.rockefeller.edu/ott/eh.htm). Linkage disequilibrium coefficients $\mathrm{D}^{\prime}=\mathrm{D} / \mathrm{Dmax}$ and $\chi^{2}$ values were calculated using the method described by Lewontin (25). The clinical and laboratory data shown in Table 1 and other nominal variables such as gender, IVIG treatment (yes or no), and timing of IVIG (early: 7 days; late: 8 days) and genotypes of two polymorphisms [VEGF g.-634 $\mathrm{G}>\mathrm{C}$ and KDR g.+4422(AC)11-14] were nominated for the evaluation of independent risk factors for CAL by stepwise logistic regression analysis. To analyze the data of dual luciferase assay, we used unpaired $t$ test. A value of $p<0.05$ was considered statistically significant.

\section{RESULTS}

Association study of two VEGF gene polymorphisms. As shown in Table 3, the frequency of $G$ allele of the g. -634 $\mathrm{G}>\mathrm{C}$ polymorphism was significantly higher in $\mathrm{KD}$ patients with CAL than that in those without CAL $[p=0.012$; odds ratio (OR) 2.1; 95\% confidence interval (CI) 1.17-3.84] or control subjects $(p=0.021$; OR $1.9 ; 95 \%$ CI $1.09-3.15)$. This was mainly because the frequency of the GG genotype was significantly higher in KD patients with CAL compared with that in $\mathrm{KD}$ patients without CAL ( $p=0.007$; OR 3.1; 95\% CI $1.34-7.03 ; p c=0.021)$. Regarding the g. $+13553 \mathrm{C}>\mathrm{T}$ polymorphism, there were no significant differences in the allele or genotype frequencies between any subject groups (data not shown).

Association study of KDR gene polymorphisms. Table 4 shows allele and genotype frequencies of KDR g. +4422(AC)11-14 polymorphism. Four types of alleles named $\mathrm{A} 1$ (11 AC repeats) to $\mathrm{A} 4$ (14 AC repeats) were identified in the Japanese population. The frequency of the A1 allele was significantly higher in the KD patients with CAL than in KD patients without CAL ( $p=0.013$; OR 2.6; $95 \% \mathrm{CI}$ 1.21-5.65). In addition, the A1 allele frequency was significantly higher in KD patients with CAL than in control subjects ( $p=0.040$; OR 2.1; 95\% CI 1.02-4.29). This was because the A1A1 genotype frequency was significantly higher in KD patients with CAL than in $\mathrm{KD}$ patients without $\mathrm{CAL}(p=$ 0.011 ; OR 3.1; 95\% CI 1.28-7.62; $p c=0.033)$. A3 and A4 alleles were very rare (each one allele in only control population). The other eight SNPs showed no association with development of CAL or occurrence of KD (data not shown).

Linkage disequilibriums of KDR gene polymorphisms. Table 5 shows that there were remarkable linkage disequilibriums between the g. +4422 (AC)11-14 polymorphism and five SNPs in the promoter region or the $\mathrm{g} .+1786 \mathrm{~T}>\mathrm{A}$ in intron 1 . In addition, these seven polymorphisms showed linkage disequilibrium from each other. In contrast, there was no linkage disequilibrium noted with the remaining two polymorphisms, g. $+11903 \mathrm{G}>\mathrm{A}$ and g. $+18487 \mathrm{~A}>\mathrm{T}$.

Allele frequencies of FLT-1 gene microsatellite polymorphism. Nine discrete alleles were identified in the Japanese population. No significant differences were observed in the allele and genotype frequencies of this polymorphism in the subject groups. Allele distribution was similar to that previously reported in the Japanese population (data not shown) (26).

Multivariate analysis of clinical and laboratory data, VEGF g. $634 \mathrm{G}>\mathrm{C}$ SNP, and KDR g.+4422(AC)11-14 polymorphism. Stepwise logistic regression analysis revealed that the A1A1 genotype of KDR g.+4422(AC)11-14, long duration of fever, and high platelet count on admission were independent parameters to predict the development of CAL in KD patients (Table 6).

Function of the KDR g.+4422(AC)11-14 polymorphic site. The KDR promoter activities with the polymorphic region (A1 and A2) were divided by that without the region and are shown as relative values in Fig. 2. The KDR promoter activity with the A1 allele was significantly higher than that with the A2 allele in HUVECs $(p=0.042)$, and there was a similar tendency in HeLa cells, as shown in Fig. 2. The SV40 promoter activities with the polymorphic region were diminished in both cells, and there were no significant differences between promoter activities with the A1 and the A2 alleles (data not shown).

Table 3. Allele and genotype frequencies of VEGF g. $-634 G>C$ polymorphisms

\begin{tabular}{lcccc}
\hline Population & $\begin{array}{c}\text { KD total } \\
(n=103)\end{array}$ & $\begin{array}{c}\text { KD (CAL }+) \\
(n=41)\end{array}$ & $\begin{array}{c}\text { KD (CAL-) } \\
(n=62)\end{array}$ \\
\hline Alleles & & & & $0.53^{*}$ \\
Controls \\
G & 0.60 & $0.71^{* \dagger}$ & 0.47 & $0.57 \dagger$ \\
C & 0.40 & 0.29 & & 0.43 \\
Genotypes & & & $0.27 \dagger$ & 0.35 \\
GG & 0.38 & $0.54 \dagger$ & 0.52 & 0.44 \\
GC & 0.45 & 0.34 & 0.21 & 0.22 \\
CC & 0.18 & 0.12 & & \\
\hline
\end{tabular}

\footnotetext{
$* p=0.012$.

$\dagger p=0.021$.

$\ddagger p c=0.021$.
} 
Table 4. Allele and genotype frequencies of KDR g.+4422(AC)11-14 polymorphisms

\begin{tabular}{|c|c|c|c|c|}
\hline Population & $\begin{array}{l}\mathrm{KD} \text { total } \\
(n=103)\end{array}$ & $\begin{array}{c}\mathrm{KD}(\mathrm{CAL}+) \\
(n=41)\end{array}$ & $\begin{array}{c}\mathrm{KD}(\mathrm{CAL}-) \\
(n=62)\end{array}$ & $\begin{array}{l}\text { Controls } \\
(n=144)\end{array}$ \\
\hline \multicolumn{5}{|l|}{ Alleles } \\
\hline A1 & 0.79 & $0.88^{* \dagger}$ & $0.73^{*}$ & $0.77 \dagger$ \\
\hline A3 & 0 & 0 & 0 & 0.003 \\
\hline A4 & 0 & 0 & 0 & 0.003 \\
\hline \multicolumn{5}{|l|}{ Genotypes } \\
\hline $\mathrm{A} 2 \mathrm{~A} 2$ & 0.05 & 0.02 & 0.06 & 0.03 \\
\hline $\mathrm{A} 2 \mathrm{~A} 3$ & 0 & 0 & 0 & 0.007 \\
\hline A1A4 & 0 & 0 & 0 & 0.007 \\
\hline
\end{tabular}

$* p=0.013$.

$\dagger p=0.04$.

$\ddagger p c=0.033$.

Table 5. KDR gene polymorphisms and their linkage disequilibriums with g. $+4422(A C) 11-14$ polymorphism

\begin{tabular}{|c|c|c|c|c|}
\hline Polymorphisms & Region & $\mathrm{D}^{\prime}$ & $\chi^{2}$ & $p$ value \\
\hline g. $+11903 \mathrm{G}>\mathrm{A}$ & Coding & 0.044 & 0.01 & 1.00 \\
\hline g. $+18487 \mathrm{~A}>\mathrm{T}$ & Coding & 0.119 & 0.29 & 0.962 \\
\hline g. $-273 \mathrm{G}>\mathrm{A}$ & Promoter & 0.814 & 60.66 & $<0.0001$ \\
\hline g. $-566 \mathrm{C}>\mathrm{T}$ & Promoter & 0.887 & 75.97 & $<0.0001$ \\
\hline g. $-608 \mathrm{~T}>\mathrm{C}$ & Promoter & 0.866 & 75.93 & $<0.0001$ \\
\hline g. $-680 \mathrm{G}>A$ & Promoter & 0.887 & 75.97 & $<0.0001$ \\
\hline g. $-907 \mathrm{~T}>\mathrm{C}$ & Promoter & 0.740 & 56.71 & 0.0001 \\
\hline g. $+1786 \mathrm{~T}>\mathrm{A}$ & Intron 1 & 0.858 & 63.46 & $<0.0001$ \\
\hline g. $+4422(\mathrm{AC}) 11-14$ & Intron 2 & - & - & - \\
\hline
\end{tabular}

$\mathrm{D}^{\prime}=\mathrm{D} / \mathrm{Dmax}$.

Table 6. Independent risk factors for CAL development by stepwise logistic regression analysis

\begin{tabular}{crcc}
\hline Risk factor & $p$ value & OR & \multicolumn{1}{c}{$95 \%$ CI } \\
\hline A1A1 genotype of KDR & 0.024 & 6.76 & $1.04-43.86$ \\
g.4422(AC)11-14 & & & \\
Long duration of fever & $<0.001$ & 2.20 & $1.31-3.71$ \\
High platelet count & 0.026 & 1.09 & $1.00-1.18$ \\
\hline
\end{tabular}

\section{DISCUSSION}

Among the pathologic findings of KD vasculitis, increased vascular permeability, which induces perivascular edema, is most vigorous on the fourth day of illness (8). The serum/ plasma VEGF levels in KD patients seem to increase in the acute or subacute stages, and they promptly decrease in convalescent stages $(11,12)$. VEGF induces the synthesis of interstitial collagenase, metalloproteinase (27), and plasminogen activators (28) and the development of fenestration in the endothelium of small venules and capillaries (29). VEGF is also a potent chemoattractant for monocytes (30) and induces expression of adhesion molecules on the endothelial cells (31). Thus, VEGF may exert its damaging effects by increasing microvascular permeability and perivascular edema through various mechanisms and may enhance vascular wall destruction in the acute KD phase and consequently be involved in the development of CAL. VEGF also enhances proliferation and migration of endothelial cells in collaboration with nitric oxide and may contribute to later vascular remodeling after the acute phase of KD $(10,32)$.

Consistent with the finding that VEGF is involved in the pathophysiology of $\mathrm{KD}$, especially in the development of CAL

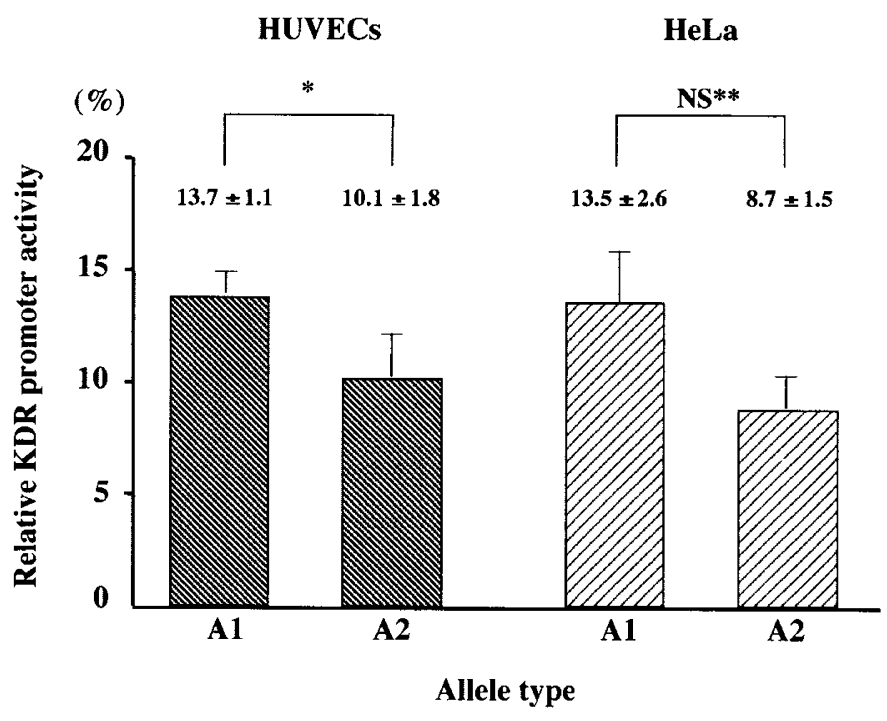

Figure 2. Relative KDR promoter activities were expressed as the ratio of the KDR promoter activities with the $\mathrm{A} 1$ or the $\mathrm{A} 2$ allele to that without the region. $* p=0.042 ; * * p=0.050$. NS, not significant.

(11-13), we showed that the frequencies of the $G$ allele of VEGF g. $-634 \mathrm{G}>\mathrm{C}$ SNP (previously described as $+405 \mathrm{G} / \mathrm{C}$ ) and the A1 allele of KDR g.+4422(AC)11-14 dinucleotide repeat polymorphism in KD patients with CAL were significantly higher than those in KD patients without CAL or control subjects.

In fact, VEGF production by LPS-stimulated mononuclear cells from individuals with the VEGF g.-634GG genotype was reported to be higher than that from those with other 
genotypes (18). In a study with a cell line, haplotypes that contained the $+405 \mathrm{G}$ (newly described as g. -634 ) allele were associated with increased basal and stimulated VEGF promoter activity and responsiveness (19). Therefore, it is presumable that the VEGF g. -634 GG genotype may affect serum/plasma VEGF levels in the acute stage of KD, although the influences of this SNP on VEGF production by vascular endothelial cells remain unknown. As for VEGF g. $+13553 \mathrm{C}>\mathrm{T}$ SNP, it was not significantly associated with the development of CAL. In a previous study, plasma VEGF levels of healthy individuals in the physiologic state were significantly lower in individuals with the VEGF g. $+13553 \mathrm{~T}$ allele than in those without it (17). A possible reason for the negative result with the VEGF g. +13553 polymorphism may be because it does not affect the transcriptional induction in a pathologic state like $\mathrm{KD}$. Because it was difficult to recruit a large number of patients with CAL, most DNA samples from CAL-positive patients were supplied by those with a history of $\mathrm{KD}$, and little acute-phase plasma or serum was available. Further prospective study with a large number of patients will help us understand the effects of this SNP on the plasma/serum VEGF levels and the development of CAL.

Two major receptors for VEGF, known as VEGF-R1 (FLT-1) and VEGF-R2 (KDR), are expressed on vascular endothelial cells. The present study has shown that KDR g. +4422 (AC) repeat polymorphism but not FLT-1 polymorphism was significantly associated with the development of CAL. KDR is the main signaling molecule of VEGF receptor, whereas FLT-1 plays a regulatory role (33). Because there were no reports on the functional significance or disease associations of the FLT-1 c. +6724 (TG)13-23 polymorphism, FLT-1 polymorphism might have less functional importance. As for six KDR SNPs in the promoter region and in intron 1 showing linkage disequilibriums with KDR g. +4422(AC) repeat polymorphism, there was no significant association between these SNPs and the development of CAL. Therefore, it is possible that this dinucleotide repeat polymorphism contributed by itself to the development of CAL. By means of the public database on the potential transcription factor binding motifs (TRANSFAC: http://transfac.gbf.de/TRANSFAC/), it was suggested that this g. +4422 (AC) polymorphism locates within the possible binding site of the aryl hydrocarbon receptor nuclear translocator (ARNT), whereas other linked SNPs were not within possible transcription factor binding sites, as shown in Fig. 3. A recent study showed that ARNT-knockout conceptus had less KDR expression in the placental labyrinth of mice (34). In addition, it is known that introns regulate gene expression as enhancer/silencer in certain cases (35-37). Therefore, it is possible that this polymorphism might influence the ARNT or ARNT-like molecule-mediated regulation of transcription, RNA elongation, or splicing of the KDR gene and consequently contribute to the development of CAL.

Multivariate analysis has first demonstrated that KDR but not VEGF polymorphism served as an independent risk factor with the highest OR among clinical, laboratory, and genetic ones for the development of CAL in KD. One possible explanation for the KDR polymorphism as the strongest independent risk factor is that KDR expression is restricted to vascular endothelial cells, which play a central role in the pathophysiology of CAL $(8,33)$.

We evaluated the functional differences of the KDR g. +4422 (AC)11-14 polymorphism between the A1 and A2 alleles by luciferase assay. The 937-bp region containing the g. +4422 (AC)11-14 polymorphism has a silencer function in HUVECs as well as HeLa cells. In addition, the A1 allele showed a significantly weaker silencer function than the A2 allele in HUVECs. Because KDR expression is limited to endothelium at the early phase in acute KD patients, it is likely that individuals with the A1A1 genotype of this polymorphism might show a higher KDR expression in the acute KD phase, increase microvascular hyperpermeability and lead to vascular injuries, which might result in the formation of CAL through the remodeling process after the acute phase.

\section{CONCLUSION}

In conclusion, Japanese KD patients with CAL showed significantly higher frequencies of the $G$ allele in VEGF
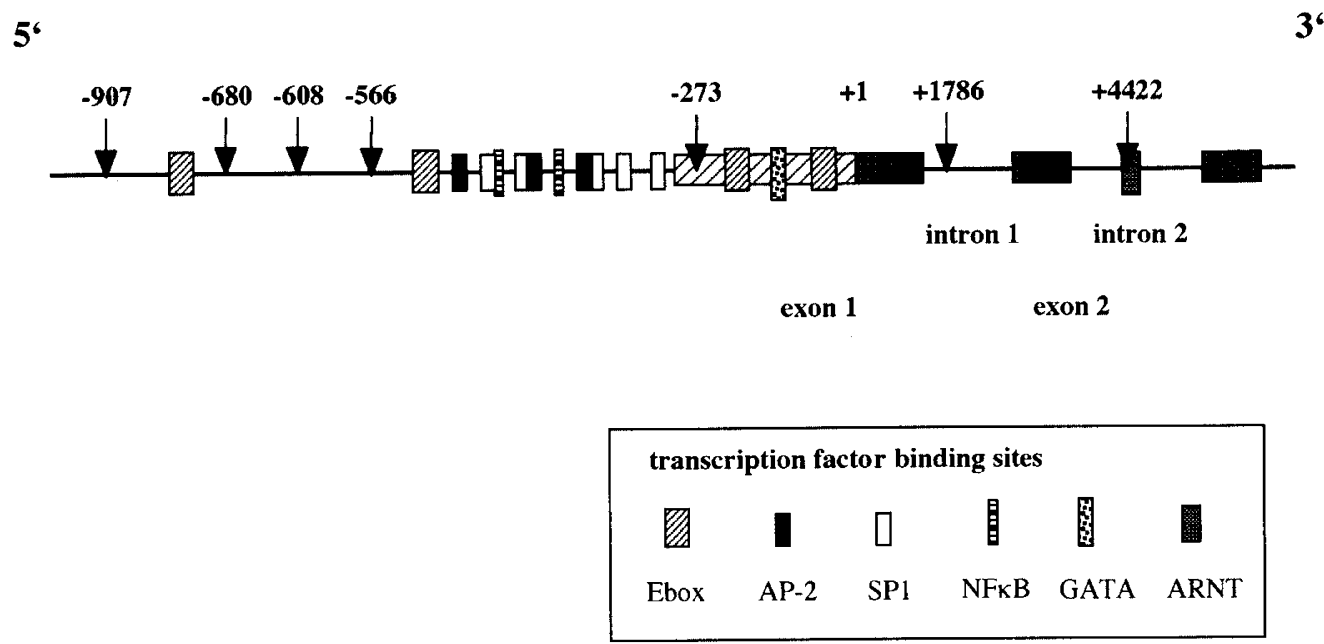

Figure 3. KDR genomic DNA and polymorphisms that showed linkage disequilibrium. The numbers and arrows show polymorphism sites, and the transcription factor binding sites are displayed as boxes. The translation start site is in exon 1 (shown as +1 ). 
g. $-634 \mathrm{G}>\mathrm{C}$ and of the A1 allele in KDR g. $+4422(\mathrm{AC}) 11-14$ polymorphisms. Particularly, the A1A1 genotype of KDR g. +4422(AC)11-14 polymorphism was an independent risk factor for the development of CAL with the highest OR by multivariate analysis. By dual luciferase assay, this KDR polymorphism might influence the VEGF effect on the endothelium through the regulation of KDR gene expression and consequently play a role in the development of CAL in KD patients. With genetic and clinical risk factors for CAL development, the more accurate and earlier prediction of CAL would be possible in KD.

\section{REFERENCES}

1. Beiser AS, Takahashi M, Baker AL, Sundel RP, Newburger JW 1998 A predictive instrument for coronary artery aneurysms in Kawasaki disease. US Multicenter Kawasaki Disease Study Group. Am J Cardiol 81:1116-1120

2. Nagashima M, Matsushima M, Matsuoka H, Ogawa A, Okumura N 1987 High-dose gammaglobulin therapy for Kawasaki disease. J Pediatr 110:710-712

3. Taubert KA, Rowley AH, Shulman ST 1991 Nationwide survey of Kawasaki disease and acute rheumatic fever. J Pediatr 119:279-282

4. Yanagawa H, Yashiro M, Nakamura Y, Kawasaki T, Kato H 1995 Results of 12 nationwide epidemiological incidence surveys of Kawasaki disease in Japan. Arch Pediatr Adolesc Med 149:779-783

5. Furukawa S, Matsubara T, Jujoh K, Yone K, Sugawara T, Sasai K, Kato H, Yabuta K 1988 Peripheral blood monocyte/macrophages and serum tumor necrosis factor in Kawasaki disease. Clin Immunol Immunopathol 48:247-251

6. Lin CY, Lin CC, Hwang B, Chiang B 1992 Serial changes of serum interleukin-6, interleukin-8, and tumor necrosis factor alpha among patients with Kawasaki disease. J Pediatr 121:924-926

7. Matsubara T, Furukawa S, Yabuta K 1990 Serum levels of tumor necrosis factor, interleukin 2 receptor, and interferon-gamma in Kawasaki disease involved coronaryartery lesions. Clin Immunol Immunopathol 56:29-36

8. Hirose S, Hamashima Y 1978 Morphological observations on the vasculitis in the mucocutaneous lymph node syndrome. A skin biopsy study of 27 patients. Eur J Pediatr 129:17-27

9. Leung DY, Geha RS, Newburger JW, Burns JC, Fiers W, Lapierre LA, Pober JS 1986 Two monokines, interleukin 1 and tumor necrosis factor, render cultured vascular endothelial cells susceptible to lysis by antibodies circulating during Kawasaki syndrome. J Exp Med 164:1958-1972

10. Hamamichi Y, Ichida F, Yu X, Hirono K, Uese KI, Hashimoto I, Tsubata S, Yoshida T, Futatani T, Kanegane H, Miyawaki T 2001 Neutrophils and mononuclear cells express vascular endothelial growth factor in acute Kawasaki disease: its possible role in progression of coronary artery lesions. Pediatr Res 49:74-80

11. Maeno N, Takei S, Masuda K, Akaike H, Matsuo K, Kitajima I, Maruyama I, Miyata K 1998 Increased serum levels of vascular endothelial growth factor in Kawasaki disease. Pediatr Res 44:596-599

12. Ohno T, Igarashi H, Inoue K, Akazawa K, Joho K, Hara T 2000 Serum vascular endothelial growth factor: a new predictive indicator for the occurrence of coronary artery lesions in Kawasaki disease. Eur J Pediatr 159:424-429

13. Terai M, Yasukawa K, Narumoto S, Tateno S, Oana S, Kohno Y 1999 Vascular endothelial growth factor in acute Kawasaki disease. Am J Cardiol 83:337-339

14. Yasukawa K, Terai M, Shulman ST, Toyozaki T, Yajima S, Kohno Y, Rowley AH 2002 Systemic production of vascular endothelial growth factor and fms-like tyrosine kinase-1 receptor in acute Kawasaki disease. Circulation 105:766-769

15. Quasney MW, Bronstein DE, Cantor RM, Zhang Q, Stroupe C, Shike H, Bastian JF, Matsubara T, Fujiwara M, Akimoto K. Newburger JW, Burns JC 2001 Increased frequency of alleles associated with elevated tumor necrosis factor-alpha levels in children with Kawasaki disease. Pediatr Res 49:686-690

16. Nishimura S, Zaitsu M, Hara M, Yokota G, Watanabe M, Ueda Y, Imayoshi M, Ishii E, Tasaki H, Hamasaki Y 2003 A polymorphism in the promoter of the CD14 gene (CD14/-159) is associated with the development of coronary artery lesions in patients with Kawasaki disease. J Pediatr 143:357-362

17. Renner W, Kotschan S, Hoffmann C, Obermayer-Pietsch B, Pilger E 2000 A common $936 \mathrm{C} / \mathrm{T}$ mutation in the gene for vascular endothelial growth factor is associated with vascular endothelial growth factor plasma levels. J Vasc Res 37:443-448

18. Watson CJ, Webb NJ, Bottomley MJ, Brenchley PE 2000 Identification of polymorphisms within the vascular endothelial growth factor (VEGF) gene: correlation with variation in VEGF protein production. Cytokine 12:1232-1235

19. Stevens A, Soden J, Brenchley PE, Ralph S, Ray DW 2003 Haplotype analysis of the polymorphic human vascular endothelial growth factor gene promoter. Cancer Res 63:812-816

20. Japanese Kawasaki Disease Research Committee 1984 The 4th revised edition of the diagnostic guidelines of Kawasaki disease. J Jpn Pediatr Soc 88:2693-2694

21. Akagi T, Rose V, Benson LN, Newman A, Freedom RM 1992 Outcome of coronary artery aneurysms after Kawasaki disease. J Pediatr 121:689-694

22. den Dunnen JT, Antonarakis S 2001 Nomenclature for the description of human sequence variations. Hum Genet 109:121-124

23. Parry RG, Gillespie KM, Clark AG, Mathieson PW 1999 Dinucleotide repea polymorphisms within the Flt-1 gene in minimal change nephropathy. Eur J Immunogenet 26:321-323

24. Patterson C, Perrella MA, Hsieh CM, Yoshizumi M, Lee ME, Haber E 1995 Cloning and functional analysis of the promoter for KDR/flk-1, a receptor for vascular endothelial growth factor. J Biol Chem 270:23111-23118

25. Lewontin RC 1964 The interaction of selection and linkage. I. General considerations; heterotic models. Genetics 49:49-67

26. Han HJ, Fujiwara T, Shin S, Nakamura Y 1993 Dinucleotide repeat polymorphism in the 3' non-coding region of the FLTI gene. Hum Mol Genet 2:2204

27. Unemori EN, Ferrara N, Bauer EA, Amento EP 1992 Vascular endothelial growth factor induces interstitial collagenase expression in human endothelial cells. J Cell Physiol 153:557-562

28. Pepper MS, Ferrara N, Orci L, Montesano R 1991 Vascular endothelial growth factor (VEGF) induces plasminogen activators and plasminogen activator inhibitor-1 in microvascular endothelial cells. Biochem Biophys Res Commun 181:902-906

29. Roberts WG, Palade GE 1995 Increased microvascular permeability and endothelial fenestration induced by vascular endothelial growth factor. J Cell Sci 108:2369-2379

30. Clauss M, Gerlach M, Gerlach H, Brett J, Wang F, Familletti PC, Pan YC, Olander JV, Connolly DT, Stern D 1990 Vascular permeability factor: a tumor-derived polypeptide that induces endothelial cell and monocyte procoagulant activity, and promotes monocyte migration. J Exp Med 172:1535-1545

31. Melder RJ, Koenig GC, Witwer BP, Safabakhsh N, Munn LL, Jain RK 1996 During angiogenesis, vascular endothelial growth factor and basic fibroblast growth factor regulate natural killer cell adhesion to tumor endothelium. Nat Med 2:992-997

32. Kimura H, Esumi H 2003 Reciprocal regulation between nitric oxide and vascular endothelial growth factor in angiogenesis. Acta Biochim Pol 50:49-59

33. Ferrara N 1999 Molecular and biological properties of vascular endothelial growth factor. J Mol Med 77:527-543

34. Abbott BD, Buckalew AR 2000 Placental defects in ARNT-knockout conceptus correlate with localized decreases in VEGF-R2, Ang-1, and Tie-2. Dev Dyn 219:526538

35. Calderwood MS, Gannoun-Zaki L, Wellems TE, Deitsch KW 2003 Plasmodium falciparum var genes are regulated by two regions with separate promoters, one upstream of the coding region and a second within the intron. $\mathrm{J}$ Biol Chem 278:34125-34132

36. Gebhardt F, Zanker KS, Brandt B 1999 Modulation of epidermal growth factor receptor gene transcription by a polymorphic dinucleotide repeat in intron 1. J Biol Chem 274:13176-13180

37. Webb KE, Martin JF, Cotton J, Erusalimsky JD, Humphries SE 2003 The 4830C >A polymorphism within intron 5 affects the pattern of alternative splicing occurring within exon 6 of the thrombopoietin gene. Exp Hematol 31:488-494 